\title{
The Relationship between Anxiety and Depression Levels with Perceived Stress and Coping Strategies in Health Care Workers during the COVID-19 Pandemic
}

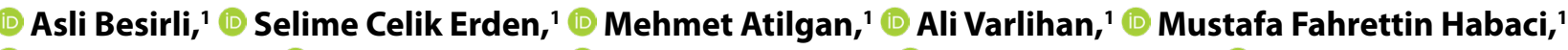

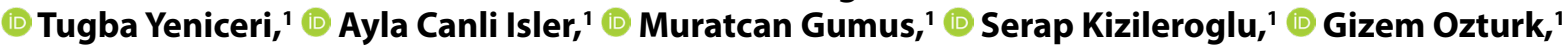 \\ (1) Omer Akil Ozer, ${ }^{1}$ (i) Haci Mustafa Ozdemir ${ }^{2}$
}

'Department of Psychiatry, University of Health Sciences Turkey, Sisli Hamidiye Etfal Teaching and Research Hospital, Istanbul Turkey ${ }^{2}$ Department of Orthopedics and Traumatology, University of Health Sciences Turkey, Sisli Hamidiye Etfal Teaching and Research Hospital, Istanbul, Turkey

\begin{abstract}
Objectives: Coronavirus disease (COVID-19) has spread rapidly, locally and internationally after it started in Hubei province of China in December 2019. During the spread of this infectious disease in the world, health care workers are taking place as the main people in the screening and treatment of the disease. The present study aims to evaluate the relationship between anxiety and depression levels with perceived stress and coping strategies in health care workers during the COVID-19 pandemic.

Methods: In this study, 200 participants were included. Beck Anxiety Inventory (BDI), Beck Depression Inventory (BDI), Perceived Stress Scale-10 (PSS-10) and COPE (Coping Orientation to Problems Experienced) were applied.

Results: Mean scores for BDI and BAI were $9.2 \pm 8.9$ and $8.2 \pm 9.2$, respectively. BDI scores of 33 (16.5\%) of 200 participants were $\geq 17.62 \%$ of the participants had minimal depression, $21.5 \%$ of the participants had mild depression, $13.5 \%$ of the participants had moderate depression, and $3 \%$ of the participants had severe depression according to BDI scores. $60.5 \%$ of the participants had minimal anxiety, $25.5 \%$ of the participants had mild anxiety, $8.5 \%$ of the participants had moderate anxiety and $5.5 \%$ of the participants had severe anxiety according to BAI scores. BAI and BDI scores of the female participants were statistically higher than the male participants. A statistically significant positive correlation was found between BAI and BDI scores and PSS-10 scores. A statistically significant difference was found in the averages of BAI and BDI, PSS-10 COPE 3 (Focus on and venting of emotions), 7 (Religious coping) and 13 (Acceptance) subscales levels in occupational groups. A statistically significant difference was found in BDI levels in the clinical units during the pandemic.

Conclusion: This study indicated that different coping strategies can be used in health care workers regarding anxiety, depression and stress levels during the COVID-19 pandemic. While problem-solving and emotion-focused adaptive coping mechanisms help reduce symptoms, maladaptive and negative coping mechanisms can cause symptoms to exacerbate. Thus, training should be given to developing attitudes of health care workers to cope with stress.

Keywords: Anxiety; coping; COVID-19; depression; perceived stress.

Please cite this article as "Besirli A, Celik Erden S, Atilgan M, Varlihan A, Habaci MF, Yeniceri T, et al. The Relationship between Anxiety and Depression Levels with Perceived Stress and Coping Strategies in Health Care Workers during the COVID-19 Pandemic. Med Bull Sisli Etfal Hosp 2021;55(1):1-11".
\end{abstract}

Address for correspondence: Asli Besirli, MD. Saglik Bilimleri Universitesi, Sisli Hamidiye Etfal Tibbi Uygulama ve Arastirma Merkezi,

Psikiyatri Kliniği, Istanbul, Turkey

Phone: +90 2123735000 E-mail: abesirli2006@yahoo.com

Submitted Date: October 12, 2020 Accepted Date: December 04, 2020 Available Online Date: March 17, 2021

${ }^{\circ}$ Copyright 2021 by The Medical Bulletin of Sisli Etfal Hospital - Available online at www.sislietfaltip.org

OPEN ACCESS This is an open access article under the CC BY-NC license (http://creativecommons.org/licenses/by-nc/4.0/). 
C oronavirus disease 2019 (COVID-19) is a pandemic in which coronavirus has been identified as the cause of the respiratory disease outbreak. ${ }^{[1]}$ It has spread rapidly, locally and internationally after it started in the Hubei province of China in December 2019. During the spread of this infectious disease in the world, health care workers are taking place as the main people in the screening and treatment of the disease. ${ }^{[2]}$

Infectious disease outbreaks have psychological effects on health care workers as well as on the general population. In studies conducted during the Severe Acute Respiratory Syndrome (SARS) outbreak in 2003, signs of acute stress response were detected in health care workers..$^{[3]}$ It has been reported that health care workers have concerns about transmitting the disease to their families, friends or colleagues; their stress levels increase, and they show symptoms of anxiety and depression. ${ }^{[4]}$ In addition, health care workers who treat patients with COVID-19 cannot escape the psychological consequences of COVID-19. ${ }^{[2]}$ Studies have also reported that they develop anxiety, ${ }_{1}^{[4]}$ experience emotional stress, ${ }^{[5]}$ perception of stigma ${ }^{[6]}$ and have clinically significant depressive symptoms..$^{[7]}$ In one study conducted during the outbreak, the findings showed that the anxiety and depression levels of surgical staff were significantly higher than before the outbreak..$^{[8]}$ Lai et al. ${ }^{[4]}(2020)$ reported in their study that 1257 health care workers had symptoms of insomnia, anxiety and depression at different levels.

In this process, health care workers face the risk of becoming infected and may be exposed to a long-term stress that hinders their coping skills. ${ }^{[1]}$ Due to the increased exposure to the virus, as it was during previous pandemics, health care workers are afraid of contracting COVID-19 disease and are concerned about transmitting the virus to their beloved ones and family members. ${ }^{[9]}$ In addition, health care workers are exposed to significant stress every day due to the loss of many patients, colleagues or friends. At the same time, health care workers who have recently started working in intensive care units may have difficulty in managing their emotions and stress since they do not have sufficient psychological training to cope with stressful working conditions. ${ }^{[10]}$

The response to stress or traumatic experiences may be different for each individual. Some individuals may respond positively while other individuals may respond negatively. Evidence suggests that the way they cope with the disease affects the life quality of the general population, and negative coping may be associated with psychological stress or anxiety and depression. ${ }^{[1]]}$

In general, coping can be classified in two ways as adaptive and maladaptive. If coping strategies are coherent with stressors (e.g., aiming to reduce emotional stress), people show fewer psychological symptoms after stressful events. Adaptive coping strategies (e.g., looking at things on the bright side) can help individuals reconstruct the meaning of life and associate the cognitive schemes about the self and the world with stressful events for better psychological adaptation. Maladaptive coping strategies (e.g., drinking as a result of avoidance behavior) are associated with life dissatisfaction and more severe psychological symptoms after stressful events. ${ }^{[12]}$

This study aims to evaluate the relationship between perceived stress and coping strategies and anxiety as well as depression levels in health care workers working in a training and research hospital during the COVID-19 pandemic.

The hypothesis of the present study is 1) Health care workers fighting against the COVID-19 pandemic are at risk regarding the development of stress and psychological symptoms, such as anxiety and depression 2) Using coping strategies helps to reduce anxiety and depressive symptoms in health care workers.

\section{Methods}

\section{Subjects}

Two hundred and ten volunteer participants from literate health care workers (e.g., physicians, nurses, health caregivers and other hospital workers, such as laboratory and radiology technicians) aged 18-65, who were actively working during the COVID-19 pandemic in a training and research hospital were considered for participation in this study on May 15-June 15 2020. All participants were evaluated by two senior psychiatrists according to the DSM-5 criteria. ${ }^{[13]}$ Health care workers who were pregnant or on leave, who were not working actively during the COVID-19 pandemic or who had schizophrenia or other psychotic disorders, alcohol and substance use disorders, mental retardation or any other conditions such as neurological diseases, or who did not agree to participate in this study were excluded. Therefore, six participants were excluded from this study because they decided to withdraw while they were filling in the scales. Four participants were excluded from this study because the were diagnosed with alcohol use disorder at the end of the psychiatric evaluation. In this study, 200 participants were included. Self-rating scales were used in this study. After giving information by the senior psychiatrists on how to fill in the scales, the participants filled in the scales by themselves.

This research was approved by the Republic of Turkey Ministry of Health. The research protocol was approved by the local ethics committee (Date: 12.05.2020, Decision Num- 
ber: 1523). The purpose and methodology of the planned research were explained to the participants and their written consent was obtained.

\section{Measurements}

Beck Anxiety Inventory (BAI): BAl is a self-evaluation scale that measures the symptoms of anxiety that an individual experiences. It was developed by Beck et al. ${ }^{[14]}$ and the validity and reliability of the Turkish version were established by Ulusoy et al. ${ }^{[15]}$

Beck Depression Inventory (BDI): BDI is a self-evaluation scale that includes 21 symptom categories and measures physical, emotional, and cognitive symptoms observed in depression. It was developed by Beck et al. ${ }^{[16]}$ and the validity and reliability of the Turkish version were established by Hisli. ${ }^{[17]}$ The cut-off point for BDI was 17 in this study.

Perceived Stress Scale-10 (PSS-10): PSS-10, developed by Cohen et al., originally consists of 14 items. It is a self-reporting scale. It measures how stressful the individual perceives some situations in life. It evaluates on a 5-point Likert-type scale in each item, varying as "Never (0)", "Almost never (1)", "Sometimes (2)", "Fairly often (3)" and "Very often (4)". There are 2 different factors in the scale: "perceived incompetence" and "perceived stress/discomfort". A maximum of 40 points in total can be obtained, and a high score means that perceived stress increases. The $4^{\text {th }}$, $5^{\text {th }}, 7^{\text {th }}$ and $8^{\text {th }}$ items are reverse scored. ${ }^{[18]}$ The Turkish adaptation of PSS-10 was made by Eskin et al. ${ }^{[19]}$ and the validity of three different forms consisting of 14,10 and 4 items was tested. A ten-item form was used in this study.

COPE (Coping Orientation to Problems Experienced): It was developed by Carver et al. ${ }^{[20]}$ in 1989. It is a self-report scale consisting of 60 questions and 15 subscales. Each subscale consists of four questions and provides information about a different coping attitude. The higher the scores to be obtained from the subscales give us the possibility to comment on which coping attitude is used more by the individual. The subscales are: 1 - Positive reinterpretation and growth, 2-Mental disengagement, 3-Focus on and venting of emotions, 4-Use of instrumental social support, 5-Active coping, 6-Denial, 7-Religious coping, 8-Humor, 9-Behavioral disengagement, 10-Restraint, 11-Use of emotional, social support, 12-Substance use, 13-Acceptance, 14-Suppression of competing activities, 15-Planning. Turkish reliability and validity studies of the scale were conducted by Ağargün et al. ${ }^{[21]}$ in 2005.

\section{Statistical Analysis}

SPSS 15.0 for Windows program was used for statistical analysis. Descriptive statistics were indicated in numbers and percentages for categorical variables and expressed concerning mean, standard deviation median, minimum and maximum values for numerical variables. As the numerical variables did not meet the normal distribution criteria, comparisons of two independent groups were made with the Mann-Whitney $U$ test. Comparisons of more than two groups were made using the Kruskal Wallis test since the numerical variables in the groups did not meet the normal distribution criteria. Subgroup analyzes were performed with the Mann-Whitney $U$ test and interpreted with Bonferroni correction. Relationships between numerical variables were analyzed using Spearman Correlation Analysis since the parametric test condition was not met. The statistical significance level of alpha was accepted as $p<0.05$.

\section{Results}

Demographic characteristics and clinical scale scores of the participants are summarized in Table 1 and Table 2.

$58.5 \%(n=117)$ of the participants were female, and $41.5 \%$ $(\mathrm{n}=83$ ) were male. The mean age was $29.5 \pm 6.4$ (Table 1).

Mean scores for BDI and BAI were 9.2 \pm 8.9 and $8.2 \pm 9.2$, respectively (Table 2). BDI scores of 33 of 200 participants were $\geq 17$ (16.5\%). (The cut-off point for BDI was 17 in this study). $62 \%$ of the participants had minimal depression, $21.5 \%$ of participants had mild depression, $13.5 \%$ of participants had moderate depression and $3 \%$ of participants had severe depression according to BDI scores.

There is not a cut-off point for the Turkish version of BAI. $60.5 \%$ of participants had minimal anxiety, $25.5 \%$ of participants had mild anxiety, $8.5 \%$ of participants had moderate anxiety and $5.5 \%$ of participants had severe anxiety according to BAI scores.

Mean BAI and BDI scores of female participants were 7 and 4 , respectively, while mean $B A I$ and $B D I$ scores of male participants were 8 and 5 , respectively. Both BAI and BDI scores of female participants were statistically higher than male participants ( $p=0.019, p=0.001$, respectively) (Table 2 ).

There were 16 participants who declared past anxiety and depressive disorders. BAI scores of two of these participants and BDI scores of three of these participants were high, but no clinical anxiety disorder, depressive disorder disorders were detected during the psychiatric evaluation.

There were five participants who were still on antidepressant treatment during the study. At the end of the psychiatric evaluation and scales applied, one participant's BAI score was high and was diagnosed with a generalized anxiety disorder and one participant had a high BDI score and was diagnosed with depressive disorder according to the DSM5 criteria. ${ }^{[14]}$ No manifest psychopathology was detected in three of the five participants after the psychiatric evaluation. 
Table 1. Demographic characteristics of the participants

\begin{tabular}{|c|c|c|}
\hline & $\mathbf{n}$ & $\%$ \\
\hline \multicolumn{3}{|l|}{ Gender } \\
\hline Female & 117 & 58.5 \\
\hline Male & 83 & 41.5 \\
\hline Age (years) & \multicolumn{2}{|c|}{$29.5 \pm 6.4(20-51)$} \\
\hline \multicolumn{3}{|l|}{ Education } \\
\hline Primary school & 5 & 2.5 \\
\hline Secondary school & 6 & 3.0 \\
\hline High school & 19 & 9.5 \\
\hline Associate degree & 13 & 6.5 \\
\hline Undergraduate & 95 & 47.5 \\
\hline Postgraduate/Doctorate & 62 & 31.0 \\
\hline \multicolumn{3}{|l|}{ Marital status } \\
\hline Single & 138 & 69.0 \\
\hline Married & 57 & 28.5 \\
\hline Divorced/other & 5 & 2.5 \\
\hline \multicolumn{3}{|l|}{ Got children } \\
\hline Yes & 37 & 18.5 \\
\hline No & 163 & 81.5 \\
\hline \multicolumn{3}{|l|}{ Living with } \\
\hline Alone & 98 & 49.0 \\
\hline Nuclear family & 93 & 46.5 \\
\hline Extended family & 9 & 4.5 \\
\hline \multicolumn{3}{|l|}{ Occupation } \\
\hline Physician & 67 & 33.5 \\
\hline Nurse & 95 & 47.5 \\
\hline Health caregiver & 22 & 11.0 \\
\hline Other hospital worker & 16 & 8.0 \\
\hline Clinical experience (years) & \multicolumn{2}{|c|}{$5.5 \pm 5.7(1-30)$} \\
\hline \multicolumn{3}{|l|}{ Working unit } \\
\hline Emergency service & 41 & 20.5 \\
\hline COVID-19 Clinics & 119 & 59.5 \\
\hline Intensive care unit & 7 & 3.5 \\
\hline Other clinics & 33 & 16.5 \\
\hline Working hours & \multicolumn{2}{|c|}{$168.3 \pm 40.4(40-360)$} \\
\hline \multirow{2}{*}{\multicolumn{3}{|c|}{$\begin{array}{l}\text { Contact with confirmed or } \\
\text { suspected cases }\end{array}$}} \\
\hline & & \\
\hline Yes & 149 & 74.5 \\
\hline Partially & 37 & 18.5 \\
\hline No & 14 & 7.0 \\
\hline \multirow{2}{*}{\multicolumn{3}{|c|}{$\begin{array}{l}\text { Suicide ideation/attempt } \\
\text { during pandemic }\end{array}$}} \\
\hline & & \\
\hline Yes & 4 & 2.0 \\
\hline No & 196 & 98.0 \\
\hline \multicolumn{3}{|l|}{ History of mental illness } \\
\hline Yes & 16 & 8.0 \\
\hline No & 184 & 92.0 \\
\hline \multicolumn{3}{|l|}{ Ongoing psychiatric treatment } \\
\hline Yes & 5 & 2.5 \\
\hline No & 195 & 97.5 \\
\hline
\end{tabular}

Table 2. Clinical Scale scores of the participants

\begin{tabular}{|c|c|c|c|}
\hline & Median (IQR) & $\mathbf{p}$ & Mean \pm SD \\
\hline \multicolumn{4}{|l|}{$\mathrm{BAI}$} \\
\hline Female & $7(3-12.5)$ & \multirow[t]{2}{*}{0.019} & \multirow[t]{2}{*}{$8.2 \pm 9.2$} \\
\hline Male & $4(2-9)$ & & \\
\hline \multicolumn{4}{|l|}{ BDI } \\
\hline Female & $8(4-15)$ & \multirow[t]{2}{*}{0.001} & \multirow[t]{2}{*}{$9.2 \pm 8.9$} \\
\hline Male & $5(1-11)$ & & \\
\hline PSS-10 & & & $19.3 \pm 6.5$ \\
\hline \multicolumn{4}{|c|}{ COPE subscales } \\
\hline \multicolumn{3}{|c|}{ 1. Positive reinterpretation and growth } & $12.9 \pm 2.1$ \\
\hline \multicolumn{3}{|c|}{ 2. Mental disengagement } & $10.3 \pm 2.4$ \\
\hline \multicolumn{3}{|c|}{ 3. Focus on and venting of emotions } & $11.0 \pm 2.2$ \\
\hline \multicolumn{3}{|c|}{ 4. Use of instrumental social support: } & $12.4 \pm 2.8$ \\
\hline \multicolumn{3}{|c|}{ 5. Active coping } & $12.3 \pm 2.3$ \\
\hline \multicolumn{3}{|c|}{ 6. Denial } & $6.6 \pm 2.5$ \\
\hline \multicolumn{3}{|c|}{ 7. Religious coping } & $11.2 \pm 4.1$ \\
\hline \multicolumn{3}{|c|}{ 8. Humor } & $9.0 \pm 3.0$ \\
\hline \multicolumn{3}{|c|}{ 9. Behavioral disengagement } & $10.1 \pm 49.8$ \\
\hline \multicolumn{3}{|c|}{ 10. Restraint } & $9.6 \pm 2.2$ \\
\hline \multicolumn{3}{|c|}{ 11. Use of emotional social support } & $11.5 \pm 2.5$ \\
\hline \multicolumn{3}{|c|}{ 12. Substance use } & $6.0 \pm 2.9$ \\
\hline \multicolumn{3}{|c|}{ 13. Acceptance } & $10.2 \pm 2.5$ \\
\hline \multicolumn{3}{|c|}{ 14. Suppression of competing activities } & $11.6 \pm 10.7$ \\
\hline \multicolumn{3}{|c|}{ 15. Planning } & $12.5 \pm 2.4$ \\
\hline
\end{tabular}

BAI: Beck anxiety inventory; BDI: Beck depression inventory; PSS10: Perceived stress scale-10; COPE: Coping orientation to problems experienced.

A statistically significant positive correlation was found between BAI and BDI scores and PSS-10 scores ( $r=0.487$, $p<0.001, r=0.537, p<0.001$, respectively) (Table 3 ).

- Negative correlation of BAI with COPE 1 (Positive reinterpretation and growth), 5 (Active coping) and 8 (Humor) subscales $(r=-0.252, p<0.001 ; r=-0.154, p=0.030$; $r=-0.186, p=0.009$, respectively),

- Positive correlation with COPE 3 (Focus on and venting of emotions) and 12 (Substance use) subscales ( $r=0.200$, $p=0.004 ; r=0.154, p=0.029$, respectively),

- Negative correlation of BDI with COPE 1 (Positive reinterpretation and growth), 5 (Active coping), 7 (Religious coping), 8 (Humor) and 15 (Planning) subscales ( $r=-$ $0.287, p<0.001 ; r=-0.256, p<0.001 ; r=-0.174, p=0.014 ; r=-$ $0.157, p=0.028 ; r=-0.169, p=0.017$, respectively),

- Positive correlation with COPE 3 (Focus on and venting of emotions), 9 (Behavioral disengagement) and 12 (Substance use) $(r=0.144, p=0.043 ; r=0.208, p=0,003$; $r=0.232, p=0.001$, respectively),

- Negative correlation of PSS-10 with COPE 1 (Positive reinterpretation and growth), 5 (Active coping) and 
Table 3. Correlations of anxiety and depression scores with perceived stress scores and coping subscales scores

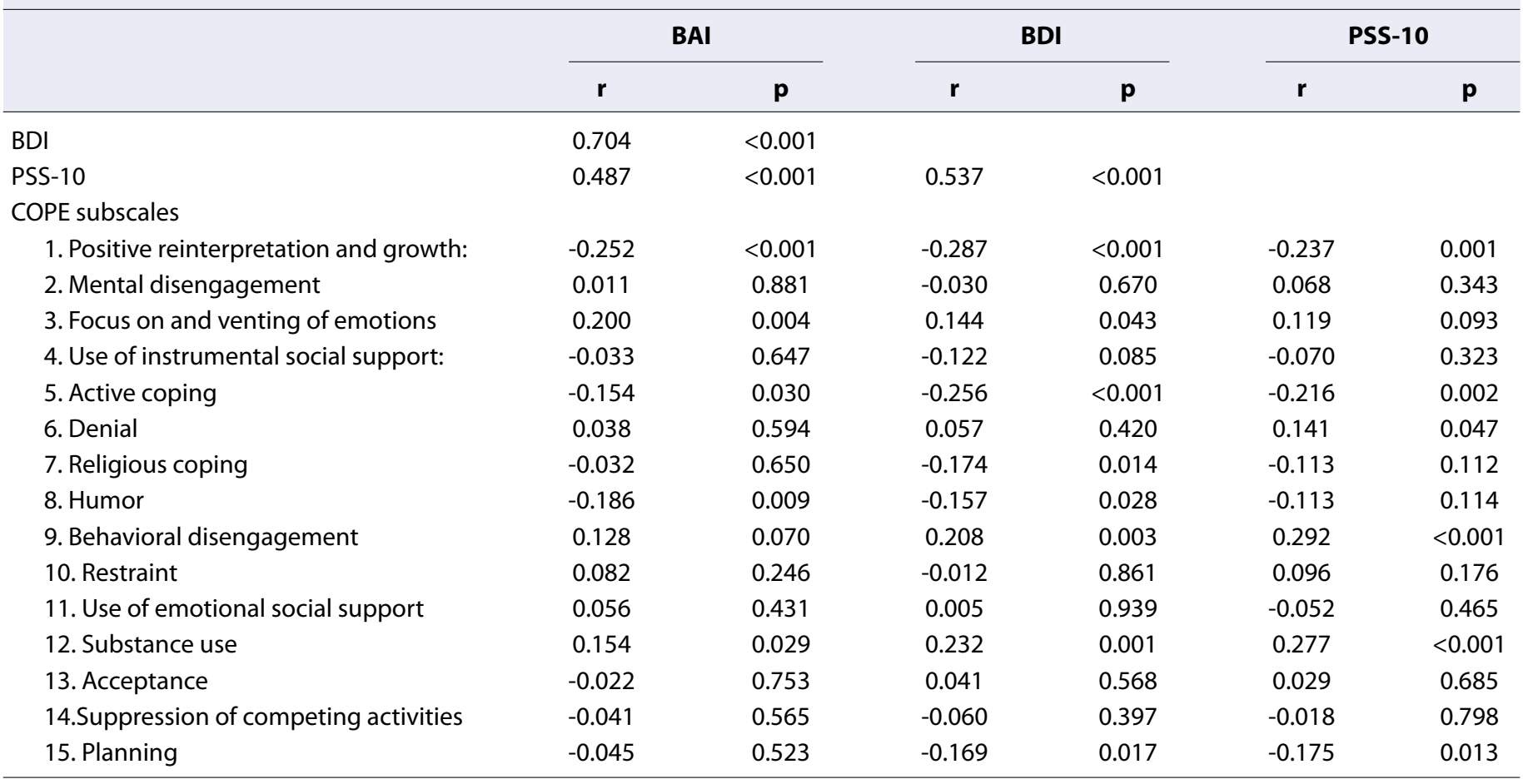

BAI: Beck anxiety inventory; BDI: Beck depression inventory; PSS-10: Perceived stress scale-10; COPE: Coping orientation to problems experienced.

15 (Planning) subscales $(r=-0.237, p=0.001 ; r=-0.216$, $p=0.002 ; r=-0.175, p=0.013$, respectively),

- Positive correlation with COPE 6 (Denial), 9 (Behavioral disengagement) and 12 (Substance use) subscales $(r=0.141, p=0.047 ; r=0.292, p<0.001 ; r=0.277, p=<0.001$, respectively) (Table 3 ).

- A statistically significant difference was found in the averages of BAI and BDI, PSS-10, COPE 3 (Focus on and venting of emotions), 7 (Religious coping) and 13 (Acceptance) subscales levels in occupational groups $(p=0.013 p=0.002 p=0.044 p=0.044 p=0.004 p=0.007$, respectively).

- BAl average of the nurses was statistically and significantly higher than physicians, BDI average of the nurses was statistically and significantly higher compared to physicians and other hospital workers, and PSS-10 and COPE 3 (Focus on and venting of emotions) scores of the nurses were statistically and significantly higher compared to the other hospital workers, respectively ( $p=0.005, p=0.005, p=0.003, p=0.014, p=0.012$, respectively).

- COPE 7 (Religious coping) scores were statistically and significantly higher in other hospital workers than physicians, as well as COPE 13 (Acceptance) scores in health caregivers compared to physicians $(p=0.003, p=0.002$, respectively) (Table 4).
A statistically significant difference was found in BDI levels in the clinical units during the pandemic $(p=0.045)$. BDI levels of those working in COVID-19 clinics were statistically significantly higher than those working in the emergency service $(p=0.009)$ (Table 5).

No statistically significant relationship was found between BAI, BDI and PSS-10 levels of the participants with age, duration of clinical experience in terms of years and working hours $(r=-0.135, p=0.057 ; r=-0.022, p=0.756 ; r=-0.066$, $p=0.350 ; r=-0.065, p=0.357 ; r=-0.009, p=0.897 ; r=-0.006$, $\mathrm{p}=0.931 ; \mathrm{r}=-0.120, \mathrm{p}=0.092 ; \mathrm{r}=-0.048, \mathrm{p}=0.496 ; \mathrm{r}=0.009$, $p=0.896$, respectively) (Table 6).

\section{Discussion}

\section{The Assessment of Anxiety, Depression and Per- ceived Stress Levels}

In this study, most of the participants had mild to moderate anxiety and depressive symptoms, while few of them had severe anxiety and depressive symptoms associated with perceived stress levels which needed treatment. Similarly, in a study, the findings showed that health care workers had symptoms of insomnia, anxiety and depression at different levels. ${ }^{[4]}$ In addition, in our study, anxiety, depression and perceived stress levels of nurses were higher than other health care workers. Thus, training programmes may be useful for them to cope with stress. 
Table 4. Comparison of the anxiety and depression, perceived stress and coping subscales scores in the occupational groups

\begin{tabular}{|c|c|c|c|c|c|c|c|c|c|}
\hline & \multicolumn{8}{|c|}{ Occupation } & \multirow[b]{3}{*}{$\mathbf{p}$} \\
\hline & \multicolumn{2}{|c|}{ Physicians } & \multicolumn{2}{|c|}{ Nurses } & \multicolumn{2}{|c|}{ Health caregivers } & \multicolumn{2}{|c|}{ Other hospital workers } & \\
\hline & Median & IQR & Median & IQR & Median & IQR & Median & IQR & \\
\hline BAI & 4 & $2-8$ & 8 & $3-14$ & 4 & $1-9.5$ & 3 & $1.25-8.25$ & 0.013 \\
\hline BDI & 7 & $2-11$ & 9 & 4-16 & 4.5 & $0.75-10$ & 2.5 & $0-9.75$ & 0.002 \\
\hline PSS-10 & 19 & $14-23.25$ & 21 & $17-24$ & 18 & $14.75-23.25$ & 16.5 & $11-22$ & 0.044 \\
\hline COPE-1 & 13 & $12-15$ & 13 & $12-14$ & 13 & $11-15.25$ & 13 & $12-15$ & 0.406 \\
\hline COPE 2 & 11 & $8-12$ & 11 & $9-12$ & 9 & 7.75-11.25 & 10 & $7.25-11$ & 0.100 \\
\hline COPE-3 & 11 & $9-13$ & 11 & $10-13$ & 10.5 & $9-13$ & 10 & $7.25-12$ & 0.044 \\
\hline COPE-4 & 13 & $10-16$ & 12 & $10-15$ & 13 & $10.75-14.25$ & 11.5 & $10.25-14.5$ & 0.656 \\
\hline COPE-5 & 12 & $11-14$ & 12 & $11-13$ & 12.5 & $10-14$ & 13 & $11.25-15.75$ & 0.606 \\
\hline COPE-6 & 6 & $4-7$ & 7 & $5-8$ & 6 & $4-9.25$ & 5 & $4-7.75$ & 0.125 \\
\hline COPE-7 & 10 & $4-15$ & 12 & $9-14$ & 13 & $10.75-15.25$ & 15.5 & $11.5-16$ & 0.004 \\
\hline COPE-8 & 9 & $7-11$ & 9 & $7-11$ & 8.5 & $7-11$ & 9 & $6-11$ & 0.804 \\
\hline COPE- 9 & 6 & $4-8$ & 6 & $5-8$ & 6.5 & 4-10 & 5.5 & $4-7.75$ & 0.637 \\
\hline COPE-10 & 10 & $9-11$ & 9 & 8-11 & 10 & 8-10.5 & 8.5 & $7-10$ & 0.260 \\
\hline COPE-11 & 12 & $10-14$ & 12 & $11-13$ & 11.5 & $10-13$ & 10.5 & $7.25-13$ & 0.617 \\
\hline COPE-12 & 4 & $4-8$ & 4 & $4-8$ & 4 & $4-8.25$ & 4 & $4-6.75$ & 0.678 \\
\hline COPE-13 & 11 & $9-12$ & 10 & $9-12$ & 9 & $6-10.25$ & 9.5 & $7-11$ & 0.007 \\
\hline COPE-14 & 11 & $9-12$ & 11 & $9-12$ & 10 & $8.75-12.25$ & 10 & $8.25-13$ & 0.940 \\
\hline COPE-15 & 13 & $11-15$ & 13 & $11-14$ & 13 & $11-15.25$ & 11.5 & $10.25-13.75$ & 0.439 \\
\hline
\end{tabular}

BAI: Beck anxiety inventory; BDI: Beck depression inventory; PSS-10: Perceived stress scale-10; COPE: Coping orientation to problems experienced.

\begin{tabular}{|c|c|c|c|c|c|c|}
\hline & BAI & BDI & PSS-10 & COPE-3 & COPE-7 & COPE-13 \\
\hline & $\mathbf{p}$ & $\mathbf{p}$ & $\mathbf{p}$ & $\mathbf{p}$ & $\mathbf{p}$ & $\mathbf{p}$ \\
\hline \multicolumn{7}{|l|}{ Physicians } \\
\hline Nurses & 0.005 & 0.005 & 0.070 & 0.154 & 0.049 & 0.096 \\
\hline Health caregivers & 0.939 & 0.573 & 0.761 & 0.594 & 0.023 & 0.002 \\
\hline Other hospital workers & 0.693 & 0.133 & 0.204 & 0.065 & 0.003 & 0.064 \\
\hline \multicolumn{7}{|l|}{ Nurses } \\
\hline Health caregivers & 0.060 & 0.038 & 0.152 & 0.155 & 0.216 & 0.020 \\
\hline Other hospital workers & 0.039 & 0.003 & 0.014 & 0.012 & 0.015 & 0.228 \\
\hline \multicolumn{7}{|l|}{ Health caregivers } \\
\hline Other hospital workers & 0.919 & 0.372 & 0.404 & 0.326 & 0.181 & 0.672 \\
\hline
\end{tabular}

In this study, the anxiety and depression levels and the perceived stress levels of the health care workers were positively correlated with each other.

In a study conducted during the COVID-19 pandemic, the findings showed that the perceived stress level had a positive effect on psychological stress, including depression and anxiety. ${ }^{[22]}$ Furthermore, stress levels and anxiety levels were positively correlated in a study conducted with nurses. ${ }^{[23]}$

Studies have been conducted in the literature examining the psychological effects of epidemics and/or pandemic outbreaks, such as SARS, MERS, COVID-19, ebola and influenza $A$, on health care workers from different groups. During these outbreaks, depressive symptoms (27.5-50.7\%), severe anxiety symptoms (45\%) and high rates of work stress were found in health care workers (18.1-80.1\%). ${ }^{[24]}$

In this study, anxiety, depression and perceived stress levels of nurses were higher than other health care workers. Thus, nurses may be trained to cope with stress. In the study conducted by Zhu J et al. ${ }^{[25]}$ (2020), the findings showed that anxiety levels of nurses were significantly higher than those of physicians consistent with the findings obtained in this study, but there was no difference in depression levels.

Lai et al. ${ }^{[4]}$ (2020) showed that anxiety and depression levels of nurses were higher than physicians during the pandem- 
Table 5. Comparison of the anxiety and depression, perceived stress and coping subscales scores in the clinical units

\begin{tabular}{|c|c|c|c|c|c|c|c|c|c|}
\hline \multicolumn{9}{|c|}{ Clinical units } & \multirow[b]{3}{*}{$\mathbf{p}$} \\
\hline & \multicolumn{2}{|c|}{ Emergency service } & \multicolumn{2}{|c|}{ COVID-19 clinics } & \multicolumn{2}{|c|}{ Other clinics } & \multicolumn{2}{|c|}{ Intensive care units } & \\
\hline & Median & IQR & Median & IQR & Median & IQR & Median & IQR & \\
\hline $\mathrm{BAI}$ & 4 & $1-8.5$ & 6 & 3-12 & 3 & $1-10$ & 4 & $2-16$ & 0.068 \\
\hline BDI & 6 & $0.5-9.5$ & 7 & $3-16$ & 5 & $1-13$ & 8 & $4-16$ & 0.045 \\
\hline PSS-10 & 18 & $14-22$ & 20 & $16-24$ & 20 & $12-23$ & 17 & $15-22$ & 0.241 \\
\hline COPE-1 & 13 & $12-15$ & 13 & $12-14$ & 13 & $12-15$ & 10 & $10-13$ & 0.088 \\
\hline COPE 2 & 11 & $9.5-12$ & 10 & 8-12 & 10 & 8-11 & 11 & $9-12$ & 0.205 \\
\hline COPE-3 & 10 & $10-12.5$ & 11 & $10-13$ & 11 & $9.5-13$ & 10 & $9-10$ & 0.158 \\
\hline COPE-4 & 13 & $11-16$ & 12 & $11-15$ & 12 & $11-13.5$ & 10 & $10-12$ & 0.137 \\
\hline COPE-5 & 12 & $11-14$ & 13 & $11-14$ & 11 & $10-14$ & 11 & $11-13$ & 0.672 \\
\hline COPE-6 & 7 & $5-8.5$ & 6 & $4-8$ & 6 & $4.5-8.5$ & 7 & $6-8$ & 0.284 \\
\hline COPE-7 & 13 & $7.5-15$ & 11 & $8-14$ & 12 & $11-16$ & 11 & 8-14 & 0.130 \\
\hline COPE-8 & 9 & $8-10$ & 9 & $7-11$ & 9 & $7-11.5$ & 10 & $9-10$ & 0.828 \\
\hline COPE- 9 & 7 & $5-8.5$ & 6 & $4-8$ & 6 & $4-8$ & 8 & $6-9$ & 0.281 \\
\hline COPE-10 & 9 & 8.5-11 & 10 & 8-11 & 10 & $9-11$ & 10 & $9-13$ & 0.351 \\
\hline COPE-11 & 12 & $9.5-14$ & 12 & $10-13$ & 11 & $9.5-13$ & 11 & $10-12$ & 0.932 \\
\hline COPE-12 & 4 & $4-6.5$ & 4 & $4-8$ & 4 & 4-7.5 & 8 & $5-9$ & 0.132 \\
\hline COPE-13 & 10 & $9-12$ & 10 & $8-12$ & 10 & $9-11$ & 10 & 8-12 & 0.797 \\
\hline COPE-14 & 11 & $9-13$ & 11 & $9-12$ & 11 & $10-12$ & 10 & $9-11$ & 0.510 \\
\hline COPE-15 & 12 & $11-14$ & 13 & $11-15$ & 12 & $11-15$ & 13 & $11-15$ & 0.860 \\
\hline
\end{tabular}

BAI: Beck anxiety inventory; BDI: Beck depression inventory; PSS-10: Perceived stress scale-10; COPE: Coping orientation to problems experienced.

\begin{tabular}{ll} 
& BECK-D \\
\cline { 2 - 2 } & $\mathbf{p}$ \\
\hline Emergency service & $\mathbf{0 . 0 0 9}$ \\
COVID clinics & 0.576 \\
Other clinics & 0.222 \\
Intensive care unit & 0.102 \\
COVID clinics & 0.919 \\
Other clinics & 0.409 \\
Intensive care unit & \\
Other clinics & \\
Intensive care unit & \\
\hline Bonferroni correction $p<0.0083$. &
\end{tabular}

ic. Cai et al. ${ }^{[5]}$ (2020) reported that nurses were more anxious and nervous than other health care workers.

Consistent with the findings of this study, other studies have shown that physicians are less psychologically affected than nurses during the epidemics/pandemics. ${ }^{[26,27]}$ This difference may originate from that nurses have more physical contact with patients compared to physicians. In addition, depression levels of health care workers working in COVID-19 clinics were higher than those working in the emergency service. Health care workers working in high-risk units and who are psychologically affected or in contact with infected patients can be shown as another factor together with the level of exposure in epidemics/ pandemics. ${ }^{[24]}$ This is consistent with the findings showing that higher risk perception may be associated with higher maladaptive responses. ${ }^{[28]}$

In this study, no significant correlation was found between sociodemographic characteristics, such as age and duration of clinical experience, concerning years and working hours with levels of anxiety and depression and perceived stress levels. Similarly, no strong evidence showing that sociodemographic factors have an effect on maladaptive psychological responses was found in other studies conducted during epidemics/pandemics. ${ }^{[24]}$ 
Table 6. Correlations of the BAI, BDI and PSS-10 levels with age, duration of clinical experience concerning years and working hours

\begin{tabular}{|c|c|c|c|c|c|c|}
\hline & \multicolumn{2}{|c|}{ Age } & \multicolumn{2}{|c|}{$\begin{array}{c}\text { Duration of } \\
\text { clinical experience } \\
\text { (years) }\end{array}$} & \multicolumn{2}{|c|}{ Working hours } \\
\hline & $\mathbf{r}$ & $\mathbf{p}$ & $\mathbf{r}$ & $\mathbf{p}$ & $\mathbf{r}$ & $\mathbf{p}$ \\
\hline $\mathrm{BAl}$ & -0.135 & 0.057 & -0.022 & 0.756 & -0.066 & 0.350 \\
\hline BDI & -0.065 & 0.357 & -0.009 & 0.897 & -0.006 & 0.931 \\
\hline PSS-10 & -0.120 & 0.092 & -0.048 & 0.496 & 0.009 & 0.896 \\
\hline
\end{tabular}

BAI: Beck anxiety inventory; BDI: Beck depression inventory; PSS-10: Perceived stress scale-10.

\section{The Relationship between Anxiety and Depression Levels with Coping Strategies}

In this study, anxiety levels were negatively correlated with "Positive reinterpretation and growth", "Active coping" and "Humor" which are the COPE subscales; and positively correlated with "Focus on and venting of emotions" and "Substance use" subscales.

"Positive reinterpretation and growth" is defined as an emotion-focused coping. It is a coping mechanism that aims to manage feelings of distress instead of dealing with stressors. This method is not limited to reducing stress. In other words, individuals are directed to continue their active, problem-focused coping actions by interpreting a stressful event in positive terms. ${ }^{[29]}$

"Active coping" is defined as a problem-focused coping. It is called actively attempting to eliminate the stressor or the improving the effects caused by the stressor. "Active coping" involves the processes of initiating the action directly, increasing effort, and trying to manage the coping attempt gradually. ${ }^{[29]}$

"Humor" coping mechanism is used to alleviate the problem. ${ }^{[30]}$

In this study, the use of three coping strategies mentioned above that can be defined as adaptive may have helped reduce anxiety levels.

Although certain stress factors are beyond problem-focused coping strategies, implementing these strategies increases the feeling of autonomy and reduces anxiety ex-

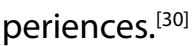

"Focus on and venting of emotions" is when a person reveals his/her emotions by focusing on stress or frustration experienced. This coping strategy can sometimes be functional, and sometimes focusing on these emotions for a long time can make it difficult to adapt. Focusing on stress can distract one from active coping. It is defined as a less useful attitude. ${ }^{[29]}$ In this study, adopting the problem-focused attitude excessively might increase anxiety levels.

"Substance use" is defined as the use of alcohol or other substances to reduce stress; ${ }^{[12]}$ however, its positive correlation with anxiety levels in this study can be interpreted as it being used as a maladaptive coping attitude to avoid anxiety.

In this study, depression levels were negatively correlated with "Positive reinterpretation and growth", "Active coping", "Religious coping", "Humor" and "Planning", which are the COPE subscales; and positively correlated with "Focus on and venting of emotions", "Behavioral disengagement" and "Substance use".

"Religious coping" is an emotion-focused coping mechanism. This mechanism can be significant for many people. People under stress can use it as a source of emotional support, such as a tool for religious reinterpretation and development, or as a source of active coping with any stressor. "Planning" is a way of thinking about how to deal with the stressor. It is a way of thinking about taking an action, finding an action strategy, what initiatives can be taken and how best to overcome the problem. It is a problem-focused coping mechanism. ${ }^{[29,30]}$

In this study, increased use of "Positive reinterpretation and growth", "Active coping", "Religious coping", "Humor" and "Planning" coping mechanisms is associated with the decrease in depression levels.

"Behavioral disengagement" is to stop putting in effort in order to deal with the stressor. It is also included among the phenomena defined as "helplessness".[29]

In this study, increased use of maladaptive coping mechanisms, such as "Focus on and venting of emotions", "Behavioral disengagement" and "Substance", may have led to an increase in depression levels.

There are different studies in the literature that may yield similar results to our findings. It was suggested that emotion-focused coping is associated with depression and anxiety and problem-focused coping is either not associated with these mood states or is negatively correlated with depressive symptoms. ${ }^{[31,32]}$ In a study conducted during the H1N1 pandemic in 2009, the findings showed that emo- 
tion-focused coping was associated with a high level of H1N1 anxiety; however, problem-focused coping was negatively correlated with anxiety. ${ }^{[33]}$

Studies conducted during the COVID-19 pandemic process yielded results consistent with the findings of this study. In a study, the findings showed that simple coping attitudes can be protective against anxiety and depression symptoms. ${ }^{[34]}$ Zhu et al. ${ }^{[25]}$ (2020) found that total positive coping scores were negatively correlated with total depression and anxiety scores, suggesting that coping mechanisms are protective factors for anxiety and depression, and positive coping mechanisms are beneficial for tough negative emotions. In another study conducted on healthcare professionals, the findings indicated that those who do not have emotional problems such as anxiety and depression use coping attitudes better than those with emotional problems. ${ }^{[35]}$ Man et al. ${ }^{[36]}$ (2020) suggested that problem-focused coping in health care workers has a significant predictive effect on anxiety and unhappiness, and they suggested that the more problem-focused coping mechanism is with the more anxiety, anger, and unhappiness. In a study conducted with student nurses during the pandemic, the findings showed that "Humor" was similarly associated with lower anxiety levels. ${ }^{[3]}$ Freud's psychodynamic perspective defines humor as one of the strongest defense mechanisms that enable individuals to face problems and avoid negative emotions, and researchers think that humor has a stress-regulating effect. ${ }^{[38]}$

\section{The Relationship between Perceived Stress and Coping Strategies}

Perceived stress scale scores in this study were negatively correlated with "Positive reinterpretation and growth", "Active coping", and "Planning", which are the COPE subscales; and positively correlated with "Denial", "Behavioral disengagement" and "Substance use".

"Denial" is an emotion-focused coping mechanism. It has often been suggested that denial is a beneficial, a stress-reducing coping mechanism that makes it easier to cope. ${ }^{[29]}$

In a study conducted with healthcare professionals during the COVID-19 pandemic, high levels of perceived stress were positively correlated with social support and problem solving, which are one of the Brief-COPE subscales; and negatively correlated with avoidance. ${ }^{[39]}$

In another study conducted with physicians, it was suggested that perceived stress has some positive effects on psychological stress, and coping mechanisms may have a regulatory effect on this correlation. ${ }^{[22]}$

In this study, one of the COPE subscales, "Focus on and venting of emotions", was statistically and significantly higher in nurses compared to other hospital workers. "Religious coping" subscale was statistically and significantly higher in other hospital workers than in physicians, and the "Acceptance" subscale in health care workers use different coping attitudes more to deal with stress.

This study has some limitations. Firstly, the sample size was relatively small and this study was a single-center study. Secondly, some results might have been affected by the data obtained in this study by self-reporting.

In conclusion, in this study, most of the participants had mild to moderate anxiety and depressive symptoms, while few of them had severe anxiety and depressive symptoms, which might be associated with perceived stress levels. Different coping attitudes can be used in health care workers regarding anxiety, depression and stress levels during the COVID-19 pandemic. Thus, training should be given to developing their attitudes to cope with stress, and psychiatric examination and treatment should be planned when necessary to help healthcare workers cope with stress during the pandemic.

\section{Disclosures}

Ethics Committee Approval: The research protocol was approved by the Local Ethics Committee (Date: 12.05.2020, Decision Number: 1523).

Peer-review: Externally peer-reviewed.

Conflict of Interest: No conflict of interest is declared by the authors.

Financial Disclosure: The authors declare that this study received no financial support.

Authorship Contributions: Concept - A.B., O.A.O., S.C.E., H.M.O.; Design - O.A.O., A.B., S.C.E., H.M.O.; Supervision - A.B., S.C.E., O.A.O., H.M.O.; Materials - A.V., T.Y., M.A., M.F.H., S.K., G.O.; Data collection \&/or processing - M.A., A.C.I., M.F.H., A.V., S.K.; Analysis and/or interpretation - A.B., S.C.E; Literature search - M.G., M.A., M.F.H., A.V., G.O., S.K., T.Y., A.C.I.; Writing - A.B., M.G.; Critical review - A.B., T.Y., A.C.I., M.G., G.O.

\section{References}

1. Zhang WR, Wang K, Yin L, Zhao WF, Xue Q, Peng M, et al. Mental Health and Psychosocial Problems of Medical Health Workers during the COVID-19 Epidemic in China. Psychother Psychosom 2020;89:242-50. [CrossRef]

2. Spoorthy MS, Pratapa SK, Mahant S. Mental health problems faced by healthcare workers due to the COVID-19 pandemic-A review. Asian J Psychiatr 2020;51:102119. [CrossRef]

3. Tam CW, Pang EP, Lam LC, Chiu HF. Severe acute respiratory syndrome (SARS) in Hong Kong in 2003: stress and psychological impact among frontline healthcare workers. Psychol Med 2004;34:1197-204. [CrossRef]

4. Lai J, Ma S, Wang Y, Cai Z, Hu J, Wei N, et al S. Factors Associat- 
ed With Mental Health Outcomes Among Health Care Workers Exposed to Coronavirus Disease 2019. JAMA Netw Open 2020;3:e203976. [CrossRef]

5. Cai H, Tu B, Ma J, Chen L, Fu L, Jiang Y, et al. Psychological Impact and Coping Strategies of Frontline Medical Staff in Hunan Between January and March 2020 During the Outbreak of Coronavirus Disease 2019 (COVID 19) in Hubei, China. Med Sci Monit 2020;26:e924171. [CrossRef]

6. Teksin G, Uluyol OB, Onur OS, Teksin MG, Ozdemir HM. Stigma-related Factors and their Effects on Health-care Workers during COVID-19 Pandemics in Turkey: A Multicenter Study. Sisli Etfal Hastan Tip Bul 2020;54:281-90. [CrossRef]

7. Liang $Y$, Chen M, Zheng X, Liu J. Screening for Chinese medical staff mental health by SDS and SAS during the outbreak of COVID-19. J Psychosom Res 2020;133:110102. [CrossRef]

8. Xu J, Xu QH, Wang CM, Wang J. Psychological status of surgical staff during the COVID-19 outbreak. Psychiatry Res 2020;288:112955.

9. Tsamakis K, Rizos E, Manolis AJ, Chaidou S, Kympouropoulos S, Spartalis $E$, et al. COVID-19 pandemic and its impact on mental health of healthcare professionals. Exp Ther Med 2020;19:3451-3.

10. Zaka A, Shamloo SE, Fiorente P, Tafuri A. COVID-19 pandemic as a watershed moment: A call for systematic psychological health care for frontline medical staff. J Health Psychol 2020;25:883-7.

11. Wang $H$, Xia $Q$, Xiong Z, Li Z, Xiang W, Yuan Y, et al. The psychological distress and coping styles in the early stages of the 2019 coronavirus disease (COVID-19) epidemic in the general mainland Chinese population: A web-based survey. PLoS One 2020;15:e0233410. [CrossRef]

12. Ye Z, Yang $X$, Zeng C, Wang Y, Shen Z, Li X, et al. Resilience, social support, and coping as mediators between COVID-19-related stressful experiences and acute stress disorder among college students in China. Appl Psychol Health Well Being 2020;12:107494. [CrossRef]

13. American Psychiatric Association. Diagnostic and Statistical Manual of Mental Disorders (DSM-5). 5th ed. Arlington: American Psychiatric Publishing; 2013. [CrossRef]

14. Beck AT, Epstein N, Brown G, Steer RA. An inventory for measuring clinical anxiety: psychometric properties. J Consult Clin Psychol 1988;56:893-7. [CrossRef]

15. Ulusoy M, Sahin NH, Erkmen H. Turkish version of the beck anxiety inventory: psychometric properties. J Cogn Psychother 1998;12:163-72.

16. Beck AT, Ward CH, Mendelson M, Mock J, Erbaugh J. An inventory for measuring depression. Arch Gen Psychiatry 1961;4:561-71.

17. Hisli N. The validity and reliability of depression inventory for university students. Turkish Journal of Psychology 1989;7:3-13.

18. Cohen S, Kamarck T, Mermelstein R. A global measure of perceived stress. J Health Soc Behav 1983;24:385-96. [CrossRef]

19. Eskin M, Harlak H, Demirkıran F, Dereboy Ç. The adaptation of the perceived stress scale into Turkish: A reliability and validity analysis. New Symposium Journal. 2013;51:132-40.
20. Carver CS, Scheier MF, Weintraub JK. Assessing coping strategies: a theoretically based approach. J Pers Soc Psychol 1989;56:26783. [CrossRef]

21. Ağargün MY, Beşiroğlu L, Kıran ÜK, Özer ÖA, Kara H. The psychometric properties of The COPE inventory in Turkish sample: a preliminary research. Anatolian Journal of Psychiatry 2005;6:221-6.

22. Wang Y, Wang P. Perceived stress and psychological distress among chinese physicians: the mediating role of coping style. Medicine (Baltimore) 2019;98:e15950. [CrossRef]

23. Mo Y, Deng L, Zhang L, Lang Q, Liao C, Wang N, et al. Work stress among Chinese nurses to support Wuhan in fighting against COVID-19 epidemic. J Nurs Manag 2020;28:1002-9. [CrossRef]

24. Preti E, Di Mattei V, Perego G, Ferrari F, Mazzetti M, Taranto P, et al. The psychological impact of epidemic and pandemic outbreaks on healthcare workers: rapid review of the evidence. Curr Psychiatry Rep 2020;22:43. [CrossRef]

25. Zhu J, Sun L, Zhang L, Wang H, Fan A, Yang B, et al. Prevalence and influencing factors of anxiety and depression symptoms in the first-line medical staff fighting against COVID-19 in Gansu. Front Psychiatry 2020;11:386. [CrossRef]

26. Alsubaie S, Hani Temsah M, Al-Eyadhy AA, Gossady I, Hasan GM, Al-Rabiaah A, et al. Middle East respiratory syndrome coronavirus epidemic impact on healthcare workers' risk perceptions, work and personal lives. J Infect Dev Ctries 2019;13:920-6. [CrossRef]

27. Goulia P, Mantas C, Dimitroula D, Mantis D, Hyphantis T. General hospital staff worries, perceived sufficiency of information and associated psychological distress during the $A / H 1 N 1$ influenza pandemic. BMC Infect Dis 2010;10:322. [CrossRef]

28. Liu X, Kakade M, Fuller CJ, Fan B, Fang Y, Kong J, et al. Depression after exposure to stressful events: lessons learned from the severe acute respiratory syndrome epidemic. Compr Psychiatry 2012;53:15-23. [CrossRef]

29. Carver CS, Scheier MF, Weintraub JK. Assessing coping strategies: a theoretically based approach. J Pers Soc Psychol 1989;56:26783. [CrossRef]

30. Litman JA. The COPE inventory: Dimensionality and relationships with approach- and avoidance-motives and positive and negative traits. Personality and Individual Differences 2006;41:273-84.

31. Anisman $H$, Matheson K. Stress, depression, and anhedonia: caveats concerning animal models. Neurosci Biobehav Rev 2005;29:525-46. [CrossRef]

32. Ben-Zur H. Coping styles and affect. International Journal of Stress Management 2009;16:87-101. [CrossRef]

33. Taha S, Matheson K, Cronin T, Anisman H. Intolerance of uncertainty, appraisals, coping, and anxiety: the case of the $2009 \mathrm{H} 1 \mathrm{~N} 1$ pandemic. Br J Health Psychol 2014;19:592-605. [CrossRef]

34. Fullana MA, Hidalgo-Mazzei D, Vieta E, Radua J. Coping behaviors associated with decreased anxiety and depressive symptoms during the COVID-19 pandemic and lockdown. J Affect Disord 2020;275:80-1. [CrossRef]

35. Dong ZQ, Ma J, Hao YN, Shen XL, Liu F, Gao Y, et al. The social psy- 
chological impact of the COVID-19 pandemic on medical staff in China: A cross-sectional study. Eur Psychiatry 2020;63:e65. [CrossRef] 36. Man MA, Toma C, Motoc NS, Necrelescu OL, Bondor Cl, Chis AF, et al. Disease perception and coping with emotional distress during COVID-19 pandemic: a survey among medical staff. Int J Environ Res Public Health 2020;17:4899. [CrossRef]

37. Savitsky B, Findling Y, Ereli A, Hendel T. Anxiety and coping strategies among nursing students during the covid-19 pandemic.
Nurse Educ Pract 2020;46:102809. [CrossRef]

38. Penson RT, Partridge RA, Rudd P, Seiden MV, Nelson JE, Chabner $B A$, et al. Laughter: the best medicine? Oncologist 2005;10:65160. [CrossRef]

39. Halayem S, Sayari N, Cherif W, Cheour M, Damak R. How Tunisian physicians of public health hospitals deal with COVID-19 pandemic: Perceived stress and coping strategies. Psychiatry Clin Neurosci 2020;74:496-7. [CrossRef] 